\title{
Sociología comparada de la vida intelectual en Argentina y Brasil (1930-1970)
}

\begin{abstract}
Reseña de: Alejandro Blanco y Luiz Carlos Jackson (2015). Sociología en el espejo. Ensayistas, científicos sociales y críticos literarios en Brasil y en la Argentina (1930-1970). Bernal: Universidad Nacional de Quilmes.
\end{abstract}

\author{
Matías Mamonde \\ Facultad de Humanidades y Ciencias de la Educación. \\ Universidad Nacional de La Plata (FaHCE - UNLP), Argentina \\ matiasmamonde90@gmail.com
}

Sociología en el espejo es el resultado de la investigación producida por Alejandro Blanco y Luiz Carlos Jackson, quienes han establecido un trabajo colaborativo en el marco del intercambio entre los miembros del grupo Prismas, de la Universidad Nacional de Quilmes (Argentina), y el Programa de Posgrado en Sociología de la Universidad de San Pablo (Brasil). Bajo la lógica de un estudio comparado a la vez histórico y sociológico, los autores recuperan los procesos que desde la década de 1950 permitieron la exitosa institucionalización de la sociología en la Argentina y Brasil.

En términos generales, aunque el análisis jerarquiza las dinámicas nacionales,los autores sitúan el proceso de institucionalización de la sociología en el marco de un contexto internacional particular que actúa como telón de fondo del análisis trazado. Por un lado la declinación en los años de la segunda posguerra de la reflexión de tipo filosófica, tanto en el espacio intelectual europeo como norteamericano, en pos de una mayor adhesión a los métodos empíricos de análisis. Por otra parte, la presión ejercida por una serie de organismos internacionales para difundir el modelo de un sistema intelectual moderno y promover el desarrollo de las ciencias y de la investigación empírica en el ámbito de las ciencias sociales. En este sentido, la División de Ciencias Sociales de la Unión Panamericana, el Departamento de Ciencias Sociales de la Organización de las Naciones Unidas para la Educación, la Ciencia y la Cultura (UNESCO), el International Social Science Council, las fundaciones Ford y Rockefeller, y la Comisión Económica para América Latina (CEPAL),son algunos de los actores internacionales atendidos por los autores.

En este marco se sitúa la indagación por la institucionalización de la sociología en los casos brasileño y argentino, que se organiza en tres capítulos. En el capítulo I los autores analizan la relación entre la naciente sociología y el género del ensayo, el cual entre las décadas de 1930 y 1940 se había constituido en Brasil y Argentina como la forma interpretativa legítima para producir análisis sobre la realidad social. Con este horizonte se reconstruye la forma específica que adquirió esta disputa por la legitimidad del análisis social en cada país, mostrando similitudes y divergencias. El principal hallazgo de esta comparación histórica radica en el hecho de que en la Argentina la disputa entre ensayistas y sociólogos fue más discreta e indirecta,aun cuando las diferencias de perspectivas entre un género y el otro fueron muy notorias. Por su parte, en Brasil, en el marco de una mayor continuidad entre ambos géneros, el debate fue enérgico y directo. Es decir que si tomamos en clave comparativa los trabajos de Gino Germani, figura relevante en la institucionalización de la sociología argentina, frente a los ensayos de mayor circulación entre los años 30 y 40, tales como Historia de una pasión Argentina (E. Mallea, 1937), El hombre que está solo y espera (R. Escalabrini Ortiz, 1931), o Radiografía de la Pampa (E. Martínez Estrada, 1933), observamos una fuerte diferenciación en sus estilos y métodos de argumentación y escritura. La orientación fuertemente literaria,autodidacta, poco sistemática,

Cita sugerida: $\square$ Mamonde, M. (2020). Sociología comparada de la vida intelectual en Argentina y Brasil (1930-1970) [Revisión del libro Sociología en el espejo. Ensayistas, científicos sociales y críticos literarios en Brasil y en la Argentina (1930-1970) por Alejandro Blanco y Luiz Carlos Jackson]. Sociohistórica, 44, e105. https://doi.org/10.24215/18521606e105 
espiritualista, y pesimista en relación con los destinos del país, que en buena medida define a la tradición del ensayo argentino en esos años, contrasta con el trabajo empírico, sociohistórico, y sistemático de Germani. Aun así su embate contra esta tradición fue sutil e indirecto.

Por otra parte los trabajos de Florestan Fernandes, principal figura de la sociología brasileña en su contexto de institucionalización, muestran una fuerte continuidad con los ensayos producidos en esa época. Producciones como Casa-grande y senzala (G. Freyre, 1933), Raizes do Brasil (S. Buarque de Holanda, 1936) o Formação do Brasil contemporáneo (C. Jr. Prado, 1942) condensan una manifiesta sensibilidad histórica y social, desarrollada en el marco de un trabajo sistemático y empíricamente argumentado. De esta manera aun cuando la sociología de Florestan Fernandes implicó la introducción de métodos, teorías y patrones de trabajo distintivos, hubo continuidad en torno a los ejes de análisis de la tradición ensayística. Sin embargo el debate entre ambas tradiciones fue de mayor intensidad.

El núcleo del capítulo se organiza para comprender esta tensión y se lo hace a través del diálogo de tres variables de análisis: la evolución de las tradiciones intelectuales de ambos países, las formas de organización académica, y las respectivas relaciones entre intelectuales y esfera política. Atendiendo al cruce de estas variables, el trabajo construye una narrativa histórica que nos lleva desde las coyunturas de las independencias hasta los años 1950, en los que la sociología se institucionaliza con éxito en ambos espacios nacionales. En ese recorrido los autores movilizan tópicos clásicos de la historia política y social de cada país, para vincular los rasgos centrales de la tradición ensayística con las dinámicas más generales del campo intelectual al que pertenecen, y sobre esta base iluminar aquella tensión inicial. De esta forma, la lógica revolucionaria o armónica que adquirieron las independencias en cada espacio,la construcción de Estados Nacionales, como también la forma centralizada o descentralizada que adquieren los sistemas intelectuales en ambos países,o la manera desigual en que los procesos de inmigración impactaron en cada caso, como así también la actitud de los ensayistas y sociólogos frente a los distintos gobiernos, son desarrollados para comprender los rasgos finales del género ensayístico en cada país, y la actitud que los sociólogos argentinos y brasileños mantendrán frente a ellos.

El capítulo II se ocupa de las trayectorias intelectuales e institucionales de Florestan Fernandes y Gino Germani, actores centrales en el proceso de institucionalización de la sociología en ambos países, y auténticos líderes de escuela, que entre los años 1950 y 1960, en San Pablo y Buenos Aires respectivamente, dirigieron proyectos académicos exitosos. El argumento del capítulo busca reconocer las condiciones históricas y sociales que favorecieron dicho éxito. Así, las dinámicas sociales y culturales de las ciudades señaladas, especialmente los procesos de inmigración, la emergencia de procesos de modernización en los sistemas universitarios, y la resultante profesionalización de la actividad intelectual dentro de ellos, resultan dimensiones fundamentales en el desarrollo del capítulo. En un lugar secundario se recupera también el impacto causado por las diversas iniciativas transnacionales que, en estos años, promovieron la modernización del conjunto de las ciencias sociales en Latinoamérica. Por último, el capítulo explora las relaciones entre la sociología y otras disciplinas como la antropología y las ciencias políticas,para el caso brasileño,y economía, historia,derecho y filosofía, para el caso argentino.

Dentro de este conjunto de relaciones interdisciplinarias el vínculo entre la sociología y la crítica literaria reviste un carácter especial, y es analizado en el capítulo III del libro. Tanto en Brasil como en la Argentina la crítica literaria se acercó a la sociología, especialmente en las décadas de 1950 y 1960, en un contexto de renovación de este campo. Así, Blanco y Jackson exponen la incorporación de los instrumentos sociológicos en el interior de ciertas iniciativas. En este sentido se recuperan la trayectorias de dos figuras centrales para la crítica literaria de ese entonces, las del argentino Adolfo Prieto y el brasileño Antonio Candido, como así también dos iniciativas culturales que en buena medida condensaron ese proceso de diálogo y acercamiento entre la crítica literaria y la sociología, Contorno (1953-1959) y Clima (1941-1944). El centro del capítulo se orienta a explicar las disímiles, y en gran medida opuestas, trayectorias de ambas figuras, para lo que se construye una explicación que entrelaza el análisis histórico del campo intelectual en el que se sitúan dichas 
trayectorias, las relaciones con el campo político, y la inserción institucional de esas disciplinas en el ámbito universitario, en la prensa y en las revistas de la época.

En suma, el trabajo de Blanco y Jackson aporta un estudio de índole programático que puede pensarse como un punto de partida pertinente para analizar otros procesos de institucionalización de la sociología en el ámbito latinoamericano en su conjunto, lo que le otorga un lugar destacado en el marco de dicha temática. Por otra parte se aprecia un tipo de análisis que no solo permite centrarse en el campo de la sociología en un contexto particular, en este caso el de su institucionalización, reponiendo sus principales referentes e iniciativas, sino que se busca interrogar ese proceso como terreno propicio para pensar en clave comparativa distintas lógicas y procesos que atraviesan al campo intelectual en general. De esta manera se orienta el interés también hacia las fronteras disciplinares,indagando en sus debates y acuerdos, hacia las relaciones entre el campo intelectual y el político, o hacia la construcción de hipótesis que vinculen aspectos de la historia social y cultural de cada país con la conformación de tradiciones de pensamiento, delineando de esta manera, al decir de los autores, una sociología comparada de la vida intelectual. 